\title{
Intravitreal Bevacizumab in Neovascular Age-Related Macular Degeneration as First Choice: a New Italian Ruling
}

\author{
Stefano Erba ${ }^{1}$, Antonio Scialdone ${ }^{1}$, Giuseppe Casalino ${ }^{1}$ \\ ${ }^{1}$ Oftalmico Hospital, ASST Fatebenefratelli Sacco, Milan, Italy.
}

\begin{abstract}
Background: Intravitreal vascular endothelial growth factor (VEGF) inhibitors represent the mainstay of neovascular agerelated macular degeneration (nAMD) treatment. Although bevacizumab has been the first anti-VEGF used in ophthalmology, it is unlicensed for intraocular use. However, the favourable cost-benefit balance has favoured its widespread use. We aimed to present relevant literature regarding the safety profile and the regulatory issues of intravitreal bevacizumab use.

Methods: In this narrative review we report relevant studies regarding the safety profile of intravitreal bevacizumab. Expert commentary is provided and an overview of the current scenario and possible future directions discussed.

Results: Randomized controlled trials have demonstrated that bevacizumab is not inferior to the licensed anti-VEGF agents showing similar efficacy and safety profiles. However, a significant debate on the regulatory issues of intravitreal bevacizumab used as 'off label' first-line treatment in nAMD still persists. Recently, the Regional Health System of Lombardia in Italy decided to only cover the expenses of bevacizumab, forcing clinicians to use bevacizumab as the first choice in the treatment of nAMD. Issues about the practical implications of this decision are discussed.

Conclusion: The use of intravitreal bevacizumab as first-line therapy in nAMD remains controversial. Many differences in the regulatory aspects still persist among the European countries and sometimes within the same countries, like Italy. Of note the clinical scenario will be modified in future by the introduction of newly developed anti-VEGF agents and anti-VEGF biosimilars.

\section{KEY WORDS}

Age-Related Macular Degeneration; Anti-Vascular Endothelial Growth Factor; Drug License Registration; Intravitreal Bevacizumab; Off-Label Use; Randomized Controlled Trial

Copyright (c) 2020, Med Hypothesis Discov Innov Ophthalmol. This is an open-access article distributed under the terms of the Creative Commons Attribution-NonCommercial 4.0 International License (http://creativecommons.org/licenses/by-nc/4.0/) which permits copy and redistribute the material just in noncommercial usages, provided the original work is properly cited.
\end{abstract}

Correspondence to: Giuseppe Casalino MD, FEBO; Oftalmico Hospital, ASST Fatebenefratelli Sacco, Piazza Principessa Clotilde n.3, 20121, Milan, Italy, E-mail: peppecasalino@gmail.com

How to cite this article: Erba S, Scialdone A, Casalino G, Intravitreal Bevacizumab in Neovascular Age-Related Macular Degeneration as First Choice: a New Italian Ruling. Med Hypothesis Discov Innov Ophthalmol. 2020; 9(3): 179-184.

\section{INTRODUCTION}

Intravitreal anti-vascular endothelial growth factor (antiVEGF) agents currently represent the mainstay of neovascular age-related macular degeneration (nAMD) treatment [1-3]. In Europe, there are three available antiVEGF agents for intravitreal use, namely bevacizumab (Avastin ${ }^{\circledR}, \quad G e n e n t e c h$ Inc./Roche), ranibizumab (Lucentis ${ }^{\circledR}$, Genentech Inc./Novartis) and aflibercept (Eylea ${ }^{\circledR}$, Regeneron/Bayer) [4]. The first evidences of activity in nAMD have been reported with systemic bevacizumab [5], which has been originally approved for the metastatic colorectal cancer and advanced breast cancer treatment [6].

Although bevacizumab has never taken the on label patent for intraocular use, its widespread use in the treatment of nAMD has been encouraged by its favourable cost. Indeed, bevacizumab is by far cheaper 
than ranibizumab and aflibercept [7], hence rapidly gained popularity among the ophthalmologists, even after the registration of ranibizumab and aflibercept for intravitreal use in nAMD $[8,9]$.

In Italy the Ministry of Health is accountable for the Italian National Health System (Sistema Sanitario Nazionale SSN) planning and for the coordination of regional activities, aimed at guaranteeing the same essential levels of care in all areas of the country. Regions are called to define their own health plans to organize health services delivery within their own territory according to the central government planning [10]. The Italian Medicine Agency (Agenzia Italiana del Farmaco - AIFA) is competent in the regulation of both approved drugs and off-label treatment. In 2018 the European Justice Court judgment expressed no objection to the use of bevacizumab for the treatment of retinal diseases [11]. Following the aforementioned judgement, in July 2019 the Region of Lombardia, one of the wealthiest and populated Italian regions, ruled to reimburse a fixed amount of 55,60 EURO for each injection in patients with nAMD, irrespective of the anti-VEGF agent used [12]. The decision has been supported by the evidence of similarity of the currently available anti-VEGF drugs in terms of safety and efficacy in nAMD, with a remarkable cost effectiveness in favour of bevacizumab $[12,13]$.

Ophthalmologists are formally free to choose either of the anti-VEGF agents available. However, since 55,60 EURO can only cover the expenses of bevacizumab, this decision has forced hospitals and healthcare organizations in Lombardia to switch to bevacizumab as first choice in nAMD. A few years before this decree in Lombardia, the Italian Regions of Emilia-Romagna and Veneto had been allowed by the AIFA to use bevacizumab for nAMD in public hospitals $[14,15]$. However, unlike the current scenario in Lombardia, the clinicians of Emilia-Romagna and Veneto have the option to get the on label anti-VEGF agents (ranibizumab and aflibercept) funded as the firstline treatment in $\mathrm{nAMD}$.

The recent decision of the Regional Health System of Lombardia has led us to briefly review the safety profile of bevacizumab and to give an overview about the pharmacology, regulatory issues and the pros and cons of intravitreal bevacizumab use in nAMD.

\section{METHODS}

This is a narrative review based on a PubMed search through April 2020 aimed at reporting relevant literature regarding the safety profile and the regulatory issues of intravitreal bevacizumab use. Reference lists were checked to identify additional relevant studies. Expert commentary is provided and an overview of the current scenario and possible future directions discussed.

\section{DISCUSSION}

\section{Pharmacology and Safety Profile}

Intravitreal anti-VEGF drugs pass in to the systemic circulation and are able to decrease the plasma-free VEGF [8], theoretically increasing the risk of systemic thromboembolic events [16]. Of note, anti-VEGF molecules containing the antibody fragment crystallizable (Fc) region (bevacizumab and aflibercept) can remain in circulation longer than the anti-VEGF agents without the Fc region (ranibizumab) [8], resulting a longer half-life, slower systemic catabolism and a stronger decrease of plasma-free VEGF.

Several randomized controlled trials (RCTs) such as the Comparison of Age-related macular degeneration Treatments Trials (CATT) study and the alternative treatments to Inhibit VEGF in Age-related choroidal Neovascularization (IVAN) study, have demonstrated that bevacizumab is not inferior to ranibizumab in the treatment of nAMD showing similar efficacy and safety profiles [17-21]. In 2014 a Cochrane systematic review of non-industry sponsored RCTs showed no statistically significant differences in deaths due to thromboembolic events such as stroke or myocardial infarction between bevacizumab and ranibizumab [22].

On the other hand, the risk of thromboembolic events could be underestimated in real life setting compared to RCTs data. Indeed, patients with history of stroke or myocardial infarction are usually excluded from sponsored multicentre clinical trials [16]. Moreover RCTs are designed to primarily assess the efficacy of drugs rather than their safety [16]. Thus, to date it is not possible to definitely answer the question whether there is a definite increased cardiovascular risk of using anti-VEGF agents in such patients who are eligible for treatment. However, pharmacokinetic/pharmacodynamic and safety data reported in both clinical trials and real world studies provide robust evidence that systemic events due to intravitreal injections are very unlikely [23] with no evidence of increased risk of death in patients [24].

At present the vials of bevacizumab are fractioned by the hospital pharmacies under sterile conditions and thereafter sent for the intravitreal use. Conversely, the vials of ranibizumab and aflibercept are prepared by an automated production line acquired directly from the manufacturer. Therefore, concern has been raised about possible microbial contamination during the compounding procedures for bevacizumab, resulting in higher levels of infectious endophthalmitis [25]. However, subsequent large data have showed that the rate of 
endophthalmitis with the pharmacy-compounded bevacizumab is not superior to single-use vials of ranibizumab [26]. Knowledge based on scientific evidence must guide our medical decisions and not the marketing status [27]. At present, there is no definite evidence-based reason not to use intravitreal bevacizumab because of systemic safety issues [7, 16] (Table 1).

Table 1: A Summary of Safety Profile of Intravitreal Bevacizumab Use in Ophthalmology

\begin{tabular}{l}
\hline Pharmacology and Safety Profile of Intravitreal Bevacizumab. \\
Intravitreal anti-VEGF drugs pass into the systemic \\
circulation and are able to decrease the plasma-free VEGF. \\
\hline RCTs showed no statistically significant differences in \\
mortality rate due to thromboembolic events between \\
bevacizumab and ranibizumab. \\
\hline CATT and IVAN studies demonstrated that bevacizumab is \\
not inferior to ranibizumab in the treatment of nAMD. \\
\hline $\begin{array}{l}\text { The rate of endophthalmitis with the pharmacy- } \\
\text { compounded bevacizumab is not superior to the single-use } \\
\text { vials of ranibizumab. }\end{array}$
\end{tabular}

Abbreviations: CATT: Comparison of Age-related macular degeneration Treatments Trials; IVAN: Inhibit VEGF in Age-related choroidal Neovascularization; nAMD: neovascular age-related macular degeneration; RCTs: randomized controlled trials; VEGF: vascular endothelial growth factor.

\section{Regulatory Issues}

In spite of the good safety profile, over the past years, the use of bevacizumab as first-line therapy in nAMD has been discouraged by many health authorities and National health systems across the world [7]. Indeed, the prescription of bevacizumab has always been limited in countries other than the United States $[28,29]$. However, the increasing demand of anti-VEGF treatment in nAMD with the resulting cost burden has led the European countries to a more liberal attitude on the use of the less expensive bevacizumab [7]. The use of an off-label drug in the presence of on-label drugs is controversial because of its regulatory and legal implications. A simple solution would have been the registration of bevacizumab for intraocular use. Roche and Genentech developed both bevacizumab and ranibizumab, respectively. As far as we know, Roche has never requested the license for intraocular use of bevacizumab.

Over the last decade we have assisted to a significant debate on the use of intravitreal bevacizumab in ophthalmology. In Italy, like in many other European countries, bevacizumab has been extensively used before the introduction of ranibizumab. Indeed, the Italian "offlabel law" $N^{\circ} 648 / 1996$ [30] allows the use of off-label drugs in absence of an on-label option and the use of bevacizumab was justified by the evidence that it was safe and more effective than the established treatment of $\mathrm{nAMD}$ at that time, namely photodynamic therapy $[5,31]$. Once ranibizumab had been marketed and approved for nAMD, in Italy the use of bevacizumab has been at first dismissed, then reintroduced with an annex of the offlabel law 648/1996 and thereafter dismissed again by the AIFA in 2012 [32].

Meanwhile, the Italian Competition Authority (Autorità Garante della Concorrenza e del Mercato - AGCM) sentenced against Roche and Novartis, respectively the owners of bevacizumab and ranibizumab, for raising unmotivated concerns about the safety of bevacizumab while promoting the more expensive ranibizumab [33]. AGCM recalled the assessment of the European Medical Agency (EMA) which did not find any greater systemic risk in the intravitreal use of bevacizumab compared to ranibizumab [34]. In 2017, the AIFA has reintroduced intravitreal bevacizumab in the list of the off-label drugs reimbursed by the SSN [35]. In November 2018 the European Court of Justice sentenced that each Country has the authority to allow the use of an off-label drug for social and economic reasons [33, 36, 37] accepting the request submitted by the AIFA in 2017.

On these grounds, in July 2019 the Local Health Authority of Lombardia decided for a massive change, economically introducing bevacizumab as the first-line treatment of nAMD with an authoritative and unprecedented straightforward policy decision in Italy [12]. It has taken a couple of months to see a "massive switch" to bevacizumab for nearly all patients with nAMD in the region.

The Regional Health System of Lombardia tracked the prescription of the intravitreal anti-VEGF agents in Lombardia before and after the decree of July 2019 [12]. Before the decree, ranibizumab, aflibercept and bevacizumab accounted for $63 \%, 37 \%$ and less than $1 \%$ of the total number of injections, respectively. In November 2019, with the full application of the decree, the prescription of anti-VEGF drugs significantly changed in favour of bevacizumab as ranibizumab, aflibercept and bevacizumab accounted for $17 \%, 8,8 \%$ and $73,2 \%$ of the total number of injections, respectively [38]. Of note, the latter data include anti-VEGF agents prescribed also for conditions other than nAMD, namely diabetic macular edema, macular edema secondary to retinal vein occlusions, and any choroidal neovascularizationassociated condition.

\section{Expert Commentary}

While this decree in Lombardia will save a large amount of health care funds, it possibly goes against the concept of personalized medicine based on patients individual needs 
by limiting the options of the clinicians in the choice of the most appropriate anti-VEGF agent. It is indeed impressive how strong may be the impact of politics, mainly driven by economic considerations, on the clinical decisions and ultimately on the health of patients.

Significant issues have been raised about the practical implications of this decree. First, at present only a limited number of hospital pharmacies in Lombardia provide bevacizumab for intravitreal use. This has led to an overload of these hospitals with an unexpected number of patients who were already under treatment with either ranibizumab or aflibercept in other centers. Second, some patients who poorly respond to one anti-VEGF agent may possibly benefit from switching to another anti-VEGF agent [39, 40]. Clinicians and the Lombardia Region authorities should come to an agreement about the switching criteria to the other anti-VEGFs in case of poor response to bevacizumab.

\section{Current trends and future directions}

In the current literature there is little evidence on such a massive switch driven by a policy decision and therefore this scenario may represent an opportunity to collect more information about the clinical course of such patients. We would like to mention the case of Sweden where a switch to bevacizumab was imposed by their health authority. While no significant drop of visual acuity was reported after the switch, $18-19 \%$ of patients were found to be non-responder to bevacizumab and switched back to ranibizumab or aflibercept [41]. Different attitudes towards the off-label use of bevacizumab in nAMD across the European Nations have been shown by a recent report [42]; indeed in Europe the use of bevacizumab in nAMD may vary considerably, ranging from non-existent (Switzerland, Hungary, Denmark) to very frequent (Romania, Bulgaria, Finland, Ireland, Netherlands). Moreover, large disparities within single countries, resulting from different organization of the National Health Systems and regional autonomies have been reported [42].

In the United Kingdom, until recent years, the General Medical Council and the National Institute for Health and Care Excellence (NICE) guidelines have not encouraged ophthalmologists to use bevacizumab in nAMD [43]. However, in September 2018, an association of 12 Local Health Authorities of the North England (namely the Clinical Commissioning Groups of the National Health Service) have obtained the legal right to use bevacizumab as the first-line treatment in nAMD [44].

Despite the favourable reports of the EMA about bevacizumab in terms of efficacy, safety and cost profiles, the attitude of the European health authorities about the use of bevacizumab in nAMD is still heterogeneous [42]. It should be noted that in future the patents of ranibizumab and aflibercept will expire and biosimilars molecules will be available for the treatment of nAMD and other retinal diseases and will possibly complicate the current scenario and its regulatory issues [45, 46].

Moreover, a newly developed anti-VEGF agent, brolucizumab (Beovu ${ }^{\circledR}$, Novartis), has been approved by the U.S. Food and Drug Administration and by the EMA for the treatment of nAMD [47]. The main advantage of Brolucizumab over the other anti-VEGFs would be the longer durability, thus having the potential to reduce the treatment burden [48, 49].

\section{CONCLUSION}

After a decade of debate about the use of on-and off-label drugs, the use of intravitreal bevacizumab as first-line therapy in $\mathrm{nAMD}$ remains controversial, in spite of its efficacy and safety profile. Over the last few years, the financial sustainability of the government-funded health care systems of the European countries has been challenged. The health care authorities will play a crucial role in exploring new ways to guarantee an effective therapy for nAMD with affordable costs. In this regard, many differences in the regulatory aspects still persist among the European countries and sometimes within the same countries, like Italy [42]. Approval of new drugs and negotiation of their cost with the pharmaceutical companies will pose additional questions. Finally, the clinical scenario will be modified in future by the introduction of anti-VEGF biosimilars, which have the potential to fill the gap between the on-label and costlier anti-VEGFs and the off-label and cheaper bevacizumab $[45,46]$.

\section{ETHICAL DECLARATIONS}

Ethical Approval: This is a narrative mini review based on other published articles and no need for ethical approval.

Conflict of Interest: None.

\section{FUNDING}

The author(s) received no specific funding for this work.

\section{ACKNOWLEDGMENTS}

We thank all the colleagues, nurses and allied health professionals working in the Medical Retina service of our Hospital. We also thank Dr. Ida Fortino from Regione 
Lombardia for sharing data about the percentage of use of the intravitreal anti-VEGF agents in Lombardia in 2019. REFERENCES

1. Rosenfeld PJ, Brown DM, Heier JS, Boyer DS, Kaiser PK, Chung CY, et al. Ranibizumab for neovascular age-related macular degeneration. N Engl J Med. 2006;355(14):1419-31. doi: 10.1056/NEJMoa054481 pmid: 17021318

2. Brown DM, Michels M, Kaiser PK, Heier JS, Sy JP, lanchulev T, et al. Ranibizumab versus verteporfin photodynamic therapy for neovascular age-related macular degeneration: Two-year results of the ANCHOR study. Ophthalmology. 2009;116(1):57-65 e5. doi: 10.1016/j.ophtha.2008.10.018 pmid: 19118696

3. Rofagha S, Bhisitkul RB, Boyer DS, Sadda SR, Zhang K, Group S-US. Seven-year outcomes in ranibizumab-treated patients in ANCHOR, MARINA, and HORIZON: a multicenter cohort study (SEVEN-UP). Ophthalmology. 2013;120(11):2292-9. doi: 10.1016/j.ophtha.2013.03.046 pmid: 23642856

4. Schwartz R, Casalino G, Chakravarthy U. Why vision loss persists in AMD. Exploring the reasons for decline in treated patients. Retinal Physician. 2019;16:32-5.

5. Rosenfeld P. Avastin in Ophthalmology: A Global Phenomenon. Available at: https://aao.org/current-insight/avastin-inophthalmology-global-phenomenon. Accessed April 2020.

6. Cilley JC, Barfi K, Benson AB, 3rd, Mulcahy MF. Bevacizumab in the treatment of colorectal cancer. Expert Opin Biol Ther. 2007;7(5):739-49. doi: 10.1517/14712598.7.5.739 pmid: 17477810

7. van Asten F, Michels CTJ, Hoyng CB, van der Wilt GJ, Klevering BJ, Rovers $M M$, et al. The cost-effectiveness of bevacizumab, ranibizumab and aflibercept for the treatment of age-related macular degeneration-A cost-effectiveness analysis from a societal perspective. PLoS One. 2018;13(5):e0197670. doi: 10.1371/journal.pone.0197670 pmid: 29772018

8. Avery RL, Castellarin AA, Steinle NC, Dhoot DS, Pieramici DJ, See R, et al. Systemic Pharmacokinetics and Pharmacodynamics of Intravitreal Aflibercept, Bevacizumab, and Ranibizumab. Retina. 2017;37(10):1847-58. doi: 10.1097/IAE.0000000000001493 pmid: 28106709

9. Heier JS, Brown DM, Chong V, Korobelnik JF, Kaiser PK, Nguyen QD, et al. Intravitreal aflibercept (VEGF trap-eye) in wet age-related macular degeneration. Ophthalmology. 2012; 119(12):2537-48. doi: 10.1016/j.ophtha.2012.09.006 pmid: 23084240

10. Cavalieri M, Gitto L, Guccio C. Reimbursement systems and quality of hospital care: an empirical analysis for Italy. Health Policy. 2013;111(3):273-89. doi: 10.1016/j.healthpol.2013.05. 014 pmid: 23830561

11. Court of Justice of the European Union. Judgment of the European court. 21 November 2018: In Case C-29/17. Novartis Farma SpA v Agenzia Italiana del Farmaco (AIFA) and Others. Available at http://curia.europa.eu/juris/liste.jsf?num=C-29/17 (link is external). Accessed April 2020.

12. Regione Lombardia. Deliberazione $\mathrm{N}^{\circ}$ XI / 1986 Seduta Del 23/07/2019; Available at: https://quotidianosanita.it/allegati/allegato6248185.pdf (link is external). Accessed April 2020.

13. Low A, Faridi A, Bhavsar KV, Cockerham GC, Freeman M, Fu R, et al. Comparative effectiveness and harms of intravitreal antivascular endothelial growth factor agents for three retinal conditions: a systematic review and meta-analysis. $\mathrm{Br} J$ Ophthalmol.
2019;103(4):442-51. doi: 10.1136/bjophthalmol-2018-312691 pmid: 30409915

14. Veneto R, Decreto N. Allestimento bevacizumab intravitrealeveneto. Regione del Veneto Coordinamento Regionale Unico sul Farmaco - CRUF. 2017;113.

15. Regione Emilia Romagna. Atti amministrativi, Giunta Regionale, Delibera Num. 581 del 15/04/2019. Available at: http://servizissiir.regione.emiliaromagna.it/deliberegiunta/servlet/AdapterHTTP?action_name=AC TIONRICERCADELIBERE\&operation=leggi\&cod_protocollo=GPG/20 19/566\&ENTE=1. (link is external). Accessed April 2020.

16. Costagliola C, Morescalchi F, Duse S, Romano D, Mazza G, Parmeggiani $F$, et al. Systemic thromboembolic adverse events in patients treated with intravitreal anti-VEGF drugs for neovascular age-related macular degeneration: an update. Expert Opin Drug Saf. 2019;18(9):803-15. doi: 10.1080/ 14740338.2019.1643838 pmid: 31309853

17. Comparison of Age-related Macular Degeneration Treatments Trials Research G, Martin DF, Maguire MG, Fine SL, Ying GS, Jaffe GJ, et al. Ranibizumab and bevacizumab for treatment of neovascular agerelated macular degeneration: two-year results. Ophthalmology. 2012;119(7):1388-98. doi: 10.1016/j. ophtha.2012.03.053 pmid: 22555112

18. Chakravarthy U, Harding SP, Rogers CA, Downes SM, Lotery AJ, Culliford LA, et al. Alternative treatments to inhibit VEGF in agerelated choroidal neovascularisation: 2-year findings of the IVAN randomised controlled trial. The Lancet. 2013;382(9900):1258-67. doi: 10.1016/s0140-6736(13)61501-9

19. Krebs I, Schmetterer L, Boltz A, Told R, Vecsei-Marlovits V, Egger S, et al. A randomised double-masked trial comparing the visual outcome after treatment with ranibizumab or bevacizumab in patients with neovascular age-related macular degeneration. $\mathrm{Br} \mathrm{J}$ Ophthalmol. 2013;97(3):266-71. doi: 10.1136/bjophthalmol-2012302391 pmid: 23292928

20. Kodjikian L, Souied EH, Mimoun G, Mauget-Faysse M, Behar-Cohen $F$, Decullier $E$, et al. Ranibizumab versus Bevacizumab for Neovascular Age-related Macular Degeneration: Results from the GEFAL Noninferiority Randomized Trial. Ophthalmology. 2013;120(11):2300-9. doi: 10.1016/j.ophtha.2013.06.020 pmid: 23916488

21. Berg K, Hadzalic E, Gjertsen I, Forsaa V, Berger LH, Kinge B, et al. Ranibizumab or Bevacizumab for Neovascular Age-Related Macular Degeneration According to the Lucentis Compared to Avastin Study Treat-and-Extend Protocol: Two-Year Results. Ophthalmology. 2016;123(1):51-9. doi: 10.1016/j.ophtha.2015. 09.018 pmid: 26477842

22. Moja L, Lucenteforte E, Kwag KH, Bertele V, Campomori A, Chakravarthy $U$, et al. Systemic safety of bevacizumab versus ranibizumab for neovascular age-related macular degeneration. Cochrane Database Syst Rev. 2014; 9: CD011230. doi: 10.1002/14651858.CD011230.pub2.

23. Baillif S, Levy B, Girmens JF, Dumas S, Tadayoni R. [Systemic safety following intravitreal injections of anti-VEGF]. J Fr Ophtalmol. 2018;41(3):271-6. doi: 10.1016/j.jfo.2017.11.006 pmid: 29567019

24. Reibaldi M, Fallico M, Avitabile T, Bonfiglio V, Russo A, Castellino N, et al. Risk of Death Associated With Intravitreal Anti-Vascular Endothelial Growth Factor Therapy: A Systematic Review and Metaanalysis. JAMA Ophthalmol. 2019. doi: 10.1001/ jamaophthalmol.2019.4636 pmid: 31750861

25. Gonzalez S, Rosenfeld PJ, Stewart MW, Brown J, Murphy SP. Avastin doesn't blind people, people blind people. Am J Ophthalmol. 
2012;153(2):196-203 e1. doi: 10.1016/j.ajo.2011. 11.023 pmid: 22264942

26. VanderBeek BL, Bonaffini SG, Ma L. Association of compounded bevacizumab with postinjection endophthalmitis. JAMA Ophthalmol. 2015;133(10):1159-64. doi: 10.1001/ jamaophthalmol.2015.2556 pmid: 26270251

27. Bonati M, Jacqz-Aigrain E, Choonara I. Licensed medicines, off-label use or evidence-based. Which is most important? Arch Dis Child. 2017;102(1):53-4. doi: 10.1136/archdischild-2016-311527 pmid: 27535476

28. Torjesen I. Why using Avastin for eye disease is so difficult. BMJ. 2012;344:e3012. doi: 10.1136/bmj.e3012 pmid: 22549057

29. Boumil MM. Off-label marketing and the First Amendment. N Engl J Med. 2013;368(2):103-5. doi: 10.1056/NEJMp1214926 pmid: 23234470

30. Repubblica Italiana. GU n.300 del 23-12-1996 Legge 23 Dicembre 1996, N.o 648.; 1996:1996 Available at: https://www.gazzettaufficiale.it/atto/serie_generale/caricaDettagli oAtto/originario?atto.dataPubblicazioneGazzetta=1996-1223\&atto.codiceRedazionale=096G0680\&elenco30giorni=false. (link is external). Accessed April 2020.

31. Michels S, Schmidt-Erfurth U, Rosenfeld PJ. Promising new treatments for neovascular age-related macular degeneration. Expert Opin Investig Drugs. 2006;15(7):779-93. doi: 10.1517/13543784.15.7.779 pmid: 16787141

32. Traversa G, Clavenna A. Lo strano caso del libro di Luca Pani. 2017:262-7. Available

at: https://ricercaepratica.it/articoli.php?archivio=yes\&vol_id=2821\&i $\mathrm{d}=28518$. Accessed April 2020.

33. Autorità Garante della Concorrenza e del Marcato (AGCM). 1760 Farmaci: Antitrust sanziona Roche e Novartis per un cartello che ha condizionato le vendite dei principali prodotti destinati alla cura della vista, Avastin e Lucentis. Oltre 180 Milioni di Euro di multa. Vol 1988.; 2014. Available at: https://www.agcm.it/media/comunicatistampa/2014/3/alias-6801. (link is external). Accessed April 2020.

34. European Medicines Agency. Committee for Medicinal Products for Human Use. Type II Variation Assessment Report. London: Avastin: Bevacizumab; 2012. Available at: https://www.ema.europa.eu/en/documents/variationreport/avastin-h-c-582-ii-0046-epar-assessment-reportvariation_en.pdf. (link is external). Accessed April 2020.

35. Repubblica Italiana. GU n. n.114 del 18-5-2017. Gazz Uff della Repubb Ital. 2017; Anno $158^{\circ}$. Availalbe at: https://www.gazzettaufficiale.it/eli/gu/2017/05/18/114/sg/pdf. (link is external). Accessed April 2020.

36. The European Parliment and of the Council. Directive 2001:83:CE.; 2001. on the Community code relating to medicinal products for human use. Available at: https://eur-lex.europa.eu/legalcontent/en/ALL/?uri=CELEX\%3A32001L0083 (link is external). Accessed April 2020.

37. The European Parliment and of the Council . Regulation (CE) N.726/2004. Vol 138.; 2004. Available at https://ec.europa.eu/health/sites/health/files/files/eudralex/vol1/reg_2004_726/reg_2004_726_en.pdf. Accessed April 2020.
38. Regione Lombardia. Intravitreal anti vegf injection, 2019 Regional survey (unpublished data, courtesy of Lombardia Region).

39. Moisseiev E, Katz G, Moisseiev J, Loewenstein A, Goldstein M, Lomnicky $Y$, et al. Switching treatment for neovascular age-related macular degeneration from bevacizumab to ranibizumab: who is likely to benefit from the switch? Retina. 2015;35(7):1323-30. doi: 10.1097/IAE.0000000000000500 pmid: 26102434

40. Ferris FL, 3rd, Maguire MG, Glassman AR, Ying GS, Martin DF. Evaluating Effects of Switching Anti-Vascular Endothelial Growth Factor Drugs for Age-Related Macular Degeneration and Diabetic Macular Edema. JAMA Ophthalmol. 2017;135(2):145-9. doi: 10.1001/jamaophthalmol.2016.4820 pmid: 28006042

41. Bro T, Hagg S. Worth changing? Clinical effects of switching treatment in neovascular age-related macular degeneration from intravitreal ranibizumab and aflibercept to bevacizumab in a region in southern Sweden. Eur J Ophthalmol. 2019:1120672119883602. doi: $10.1177 / 1120672119883602$ pmid: 31642333

42. Bro T, Derebecka M, Jorstad OK, Grzybowski A. Off-label use of bevacizumab for wet age-related macular degeneration in Europe. Graefes Arch Clin Exp Ophthalmol. 2020;258(3):503-11. doi: 10.1007/s00417-019-04569-8 pmid: 31889214

43. NICE GUIDELINE. Age-related macular degener degeneration ation. $2018 . \quad$ Available at https://www.nice.org.uk/guidance/ng82/resources/agerelatedmacular-degeneration-pdf-1837691334853 (link is external). Accessed April 2020.

44. Cohen D. CCGs win right to offer patients Avastin for wet AMD. BMJ 2018;362:k4035. doi: 10.1136/bmj.k4035 pmid: 30249782

45. Sharma A, Reddy P, Kuppermann BD, Bandello F, Lowenstein A. Biosimilars in ophthalmology: "Is there a big change on the horizon?". Clin Ophthalmol. 2018;12:2137-43. doi: 10.2147/OPTH.S180393 pmid: 30498330

46. Sharma A, Kumar N, Kuppermann BD, Bandello F, Loewenstein A. Understanding biosimilars and its regulatory aspects across the globe: an ophthalmology perspective. $\mathrm{Br} J$ Ophthalmol. 2020;104(1):2-7. doi: 10.1136/bjophthalmol-2019-314443 pmid: 31315829

47. Human medicine European public assessment report (EPAR): Beovu. Available at https://ema.europa.eu/en/medicines/human/EPAR/beovu (link is external). Accessed April 2020.

48. Dugel PU, Koh A, Ogura Y, Jaffe GJ, Schmidt-Erfurth U, Brown DM, et al. HAWK and HARRIER: Phase 3, Multicenter, Randomized, DoubleMasked Trials of Brolucizumab for Neovascular Age-Related Macular Degeneration. Ophthalmology. 2020;127(1):72-84. doi: 10.1016/j.ophtha. 2019.04.017 pmid: 30986442

49. Nguyen QD, Das A, Do DV, Dugel PU, Gomes A, Holz FG, et al. Brolucizumab: Evolution through Preclinical and Clinical Studies and the Implications for the Management of Neovascular Age-Related Macular Degeneration. Ophthalmology. 2020. doi: 10.1016/j.ophtha.2019.12.031 